\title{
Advances of Forensic Science in India
}

\author{
Amarnath Mishra \\ Amity Institute of Forensic Sciences, Amity University UP, Noida, India
}

Email: drmishraa1@gmail.com

Crime is as old as civilization itself. The clear aim was to recognize the people who do not go behind the lay down norms, penalize them and isolate them from the mainstream and therefore keep the society clean. This gave birth to the processes of discovery and investigation of crime and administration of criminal justice, which in order, led to the establishment of institution for investigation, trial and for imparting impartiality. The dependence on 'eyewitnesses' did not prove to be effective, as they were found to turn hostile, many a time due to threat to life or temptation of money. The crime investigators then resorted to 'third degree methods' for the examination of the suspect to reveal the truth which due to the cultural change and values accepted generally, were considered cruel, as many innocent people also suffered and sometimes inadvertently. In the meantime, a lot of scientific research and development took place, and it was then visualized that the modern scientific techniques could provide quick solution to a majority of problem of human being and therefore, crime investigation of 'forensic science' got evolved.

Advances in Forensic Science in India have come a long way and probably still have more to go. Collecting materials from the crime spot and taking the same to crime laboratory, gathering all clues and converting them into evidences which are admissible in court is a crucial job for a forensic scientist. There is no reason to limit our view on other situations that also may help improve the way work is being done. One of them is the research that must be developed in the education of future forensic aspirants. Most universities that teach these young people during their various years of formation, include in the curriculum characteristics that they consider must be present by the time they finish their schooling, such as a multi-disciplinary vision that integrates the analysis of the crime from its beginning as well as the capacity to apply the adequate methods and techniques in processing traces of physical evidence and be capable of discerning what is important at the scene of the crime as well as include the diverse aspects of the victim, the culprit, the context and social and psychological aspects associated with the crime. Adding to this, they consider the importance of following procedures being able to support the findings and acting in an ethical and professional manner. They include in their considerations the development of abilities to work with others, to possess the capacity to resolve problems, to be creative, to have sufficient social abilities that help them to learn during all their professional life as well as to possess an adequate continuous personal growth. But there are no studies published that sustain that the students have developed these abilities now considered vital in the inclusion of competencies as part of the methods of teaching and learning. The implementation of competencies has surpassed the barrier of industry and is now considered in many different areas of knowledge as an important method of teaching that has to be assed regularly by teachers and officials in many graduate and postgraduate courses. Among these competencies we can observe the presence of communication abilities, critical thinking and personal development and growth that must be evaluated in each future forensic professional. Some of the principals involved are mentioned in theory in documents but are not published studies to analyses how the students are responding to interventions in these areas or to observe different methods and their results when applied during their school years. This is important because technology is only one part of the process of the forensic field, the other are the people that apply it and therefore, their capacity must be encouraged and assed to further correct and stimulate them through adequate methods that enhance their abilities. This will help teachers to center their efforts in the direction needed to obtain these goals Therefore education must be considered valuable and commands respect and a place in our research to offer other professionals new instruments to better the future of the forensic aspirants.

\section{References}

1. Nanda BB and Tiwari RK, Forensic Science in India, a Vision for the Twenty- First Century (Select Publishers, New Delhi, 2001).

2. Turner RF (1975) Forensic science education: A perspective. En: Davies G (editor) Forensic science. ACS Symposium Series, No. 13. Washington, D.C, American Chemical Society, p: 1-7. 